\title{
Effect of Dyslipidaemia on Arrhythmia in Diabetic Patients
}

\author{
${ }^{*}$ Hoque $S J^{1}$, Rahman $A^{2}$, Miah $M B^{3}$, Alam $M Z^{4}$, Irfan $S M R^{5}$, Safdar $A M B^{6}$
}

\begin{abstract}
Dyslipidaemia is an important risk factor for cardiovascular morbidity and mortality. This cross-sectional study aims to find out the effect of dyslipidaemia on arrhythmia in diabetic patients. A total of sixty (60) diabetic patients, 31 were male and 29 were female, mean age was $59.58 \pm 11.38$ (range 40 to 84) years with arrhythmia were selected at the department of Cardiology at Bangladesh Institute of Research and Rehabilitation in Diabetes, Endocrine and Metabolic Disorder(BIRDEM) General Hospital, Dhaka over a period of six months from January to July 2014. All the patients were accomplished with 24 hours Holter ECG monitoring, among them 40 were dyslipidaemia with mean age $60.7 \pm 13$. 1years and 20 were without dyslipidaemia with mean age $58 \pm 10.3$ years (p-value was 0.424). Mean pulse, systolic and diastolic blood pressure were $78 \pm 15$ (range 55-98) beats $/ \mathrm{min}, 132 \pm 20$ (range 90-180) $\mathrm{mm}$ of $\mathrm{Hg}$ and $79 \pm 8$ (range 60-100) $\mathrm{mm}$ of $\mathrm{Hg}$ respectively. Mean maximum and minimum heart rate were $114 \pm 22$ and $57 \pm 14$ beats respectively. Mean cholesterol level was $222.58 \pm 55.51 \mathrm{mg} / \mathrm{dl}$, mean triglyceride
\end{abstract}

1. *Dr. Shabnam Jahan Hoque, Junior Consultant, Department of Cardiology, BIRDEM General Hospital \& Ibrahim Medical College, Email: sjahanhoque@yahoo.com

2. Dr. Aparna Rahman, Senior Medical Officer, Dept. of Cardiology, BIRDEM General Hospital \& Ibrahim Medical College.

3. Dr. Md. Babul Miah, Senior Medical Officer, Dept. of Cardiology, BIRDEM General Hospital \& Ibrahim Medical College.

4. Dr. Md. Zahid Alam, Associate Professor, Dept. of Cardiology, BIRDEM General Hospital \& Ibrahim Medical College.

5. Dr. SM Rezaul Irfan, Junior Consultant, Dept. of Cardiology, BIRDEM General Hospital \& Ibrahim Medical College.

6. Dr. AMB Safdar, Associate Professor, Dept. of Cardiology, BIRDEM General Hospital \& Ibrahim Medical College.

${ }^{*}$ Corresponding Author:
$241.26 \pm 98.81 \mathrm{mg} / \mathrm{dl}, \mathrm{LDL} 135.53 \pm 35.61 \mathrm{mg} / \mathrm{dl}$ and $H D L$ $41.46 \pm 15.46 \mathrm{mg} / \mathrm{dl}$. Mean supraventricular beats in 24 hours

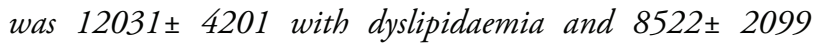
without dyslipidaemia which was statistically significant. Mean ventricular beats in 24 hours was $13472 \pm 4872$ with dyslipidaemia and $8754 \pm 2689$ without dyslipidaemia which was also statistically significant. Arrhythmia was found more common among diabetic patients having dyslipidaemia than without dyslipidaemia.

Key Words: arrhythmia, diabetes mellitus, 24 hours holter monitoring, ischaemic heart disease (IHD).

\section{INTRODUCTION:}

Dyslipidaemia is one of the important modifiable risk factor for cardiovascular disease morbidity and mortality. 1 Cardiovascular disease remains the single most common cause of death in developed nations.2,3 Sudden death from cardiac causes is estimated to account for approximately 50 percent of all deaths.2,3 The majority of such sudden deaths are caused by acute ventricular tachyarrhythmias, which may occur in persons without known cardiac disease or in association with structural heart disease.2-4 Lipid-lowering interventions have been shown to reduce coronary events and all-cause mortality.5-7 It is possible that some of the beneficial effects of lipid-lowering therapy can be attributed to the reduction of ventricular arrhythmias and sudden death. 5,7

Holter monitoring technologies and loop recorders allow prolonged monitoring of heart rhythm for periods from a few days to several months, making it possible to detect infrequent arrhythmias in patients of all ages. 8 Cardiac rhythm monitoring has an established diagnostic and prognostic role in different circumstances: syncope, palpitations and monitoring of patients with known or suspected episodes of atrial fibrillation (AF), e.g. those with stroke of uncertain aetiology (cryptogenic stroke).9-11

There might be an association between dyslipidaemia and arrhythmia. However, no data are available regarding the direct relationship between dyslipidaemia and arrhythmia, especially in the clinical setting of acute coronary syndrome. One recently completed study showed that hypercholesterolemia could induce proarrhythmic neural and electrophysiologic remodeling in myocardium.12 This remodeling induced by hypercholesterolemia is characterized by heterogeneous nerve sprouting and sympathetic hyperinnervation, which may contribute to the 
dispersion of repolarization during sympathetic activation. In addition, hypercholesterolemia apparently can directly remodel membrane currents. The alteration in membrane current is associated with prolonged actionpotential duration, longer QTc intervals, and increased repolarization dispersion. The purpose of this study was to observe any association of dyslipidaemia with arrhythmia.

\section{METHODOLOGY:}

This cross-sectional study was carried out in the department of Cardiology at Bangladesh Institute of Research and Rehabilitation in Diabetes, Endocrine and Metabolic Disorder (BIRDEM) General Hospital, Dhaka, Bangladesh from January to July 2014. Purposive sampling was done among 60 adult diabetic patients, age $>18$ years of either sex having Diabetes mellitus along with arrhythmia were included in this study. Non-diabetic patients, patients with electrolyte imbalance and those who were not willing to participate in the study were excluded. After enrollment all patients were evaluated clinically by taking history and physical examination. After taking informed consent, data were collected regarding smoking history, history of Hypertension, IHD. Pulse, systolic and diastolic pressure were recorded in all cases. Among all cases 24 hours holter ECG monitoring was done. After collection of blood, fasting blood glucose, HbA1c, lipid profile (serum cholesterol, Triglyceride, HDL, LDL) were measured and recorded accordingly. Dyslipidaemia was considered according to ATP III guideline with Serum Total cholesterol $>200 \mathrm{mg} / \mathrm{dl}$, TG $>150 \mathrm{mg} / \mathrm{dl}, \mathrm{LDL}>100 \mathrm{mg} / \mathrm{dl}$, HDL $<40 \mathrm{mg} / \mathrm{dl}$ (male) and $<50 \mathrm{mg} / \mathrm{dl}$ (female). Ethical permission was approved by appropriate authority. Data were analyzed using SPSS version 17.0 and $p$ value $<0.05$ was considered as significant.

\section{RESULTS:}

Among the total 60 cases, mean age was $59.58 \pm 11.38$ (range 40-84) years. Eighty percent of the study population were 50 years and above. Among the study population, 26.67\% were smoker. Common co-morbidities were hypertension $83.30 \%$, Ishemic heart diseases $86.6 \%$ and dyslipidaemia in $66.7 \%$ (40) patients. Among the total 60 cases $36.67 \%$ subjects were found in adequate glycemic control and $63.33 \%$ were not in adequate glycemic control. Mean pulse, systolic and diastolic blood pressure were $78 \pm 15$ (range 55-98) beats/min, $132 \pm 20$ (range $90-180$ ) $\mathrm{mm}$ of $\mathrm{Hg}$ and $79 \pm 8$ (range $60-100$ ) $\mathrm{mm}$ of $\mathrm{Hg}$ respectively. Various types of arrhythmia were observed. Ventricular ectopy, supraventricular ectopy, atrial fibrillation and sinus pause were present in $100 \%, 71.67 \%, 8.33 \%$ and $5 \%$ cases respectively. In case of ventricular ectopics $40.0 \%$ subjects had single PVC's, $20.0 \%$ had triplets, $16.67 \%$ had couplets, $15.0 \%$ had trigeminy, $13.33 \%$ had bigeminy, $13.33 \%$ had ventricular run and $06.65 \%$ had late VE's (Table II). In case of supraventricular ectopic $43.33 \%$ had single PAC's,
$33.33 \%$ had atrial run, $25 \%$ had atrial pairs, $18.33 \%$ had bigeminy, $15.00 \%$ had late beats, $13.33 \%$ had trigeminy and $11.67 \%$ had drob beats (Table-III). Mean age was found $60.7 \pm 13.1$ years and $58.0 \pm 10.3$ years in groups with and without dyslipidaemia respectively (Table-IV). Twenty three $(57.5 \%)$ patients were male in dyslipidaemia group and $8(40.0 \%)$ in group without dyslipidaemia (Table-V) which were not statistically significant $(\mathrm{p}>0.05)$. Mean cholesterol, TG, HDL and LDL were not statistically significant ( $>0.05$ ) between male and female groups (Table-VI). Significant difference was found in mean total ventricular beats and mean supraventricular beats between groups with and without dyslipidaemia (Table-VII \&VIII).

Table- I: Baseline biochemical parameters of the study population $(\mathrm{n}=60)$

\begin{tabular}{lcc}
\hline Parameters & Mean \pm SD & Minimum-Maximum \\
\hline FBG $(\mathrm{mmol} / \mathrm{l})$ & $19.32 \pm 10.2$ & $5.5-35.3$ \\
Hb Alc $(\%)$ & $12.34 \pm 5.8$ & $6.7-18.4$ \\
Cholesterol $(\mathrm{mg} / \mathrm{dl})$ & $222.58 \pm 55.51$ & $99-345$ \\
Triglyceride $(\mathrm{mg} / \mathrm{dl})$ & $241.26 \pm 98.81$ & $113-540$ \\
HDL $(\mathrm{mg} / \mathrm{dl})$ & $41.46 \pm 15.46$ & $19-68$ \\
LDL $(\mathrm{mg} / \mathrm{dl})$ & $135.53 \pm 35.61$ & $111-189$ \\
\hline
\end{tabular}

Table- I represents distribution by the bio-medical parameters where fasting blood glucose was within 5.5 to $35.3 \mathrm{mmol} / \mathrm{l}$, Hb A1C was within 6.7-18.4(\%). Mean cholesterol was $222.58 \pm 55.51 \mathrm{mg} / \mathrm{dl}$, triglygeride was $241.26 \pm 98.81 \mathrm{mg} / \mathrm{dl}$, High density lipoprotien and low density lipoprotien was $41.46 \pm 15.46 \mathrm{mg} / \mathrm{dl}$ and $135.53 \pm$ $15.46 \mathrm{mg} / \mathrm{dl}$ respectively.

Table- II: Findings of different type of ventricular ectopics in all cases on 24 hours Holter monitoring $(n=60)$

\begin{tabular}{lrr}
\hline Events & Number & Percentage \\
\hline Single PVC's & 24 & 40.00 \\
Triplets & 12 & 20.00 \\
Couplets & 10 & 16.67 \\
Trigeminy & 09 & 15.00 \\
Bigeminy & 08 & 13.33 \\
Ventricular run & 08 & 13.33 \\
Late VE's & 04 & 06.65 \\
\hline Mean \pm SD total ventricular beats & $3019 \pm 889(19336-15)$ \\
in 24 hours (Maximum Minimum) &
\end{tabular}


Table- III: Findings of diferrent type of supraventricular ectopy in 43 cases on 24 hours holter monitoring $(\mathrm{n}=60)$

\begin{tabular}{lrc}
\hline Events & Number & Percentage \\
\hline Single PAC's & 26 & 43.33 \\
Atrial run & 20 & 33.33 \\
Atrial pairs & 15 & 25.00 \\
Bigeminy & 11 & 18.33 \\
Late & 09 & 15.00 \\
Trigeminy & 08 & 13.33 \\
Drop & 07 & 11.67 \\
\hline Mean \pm SD total supraventricular beats & $4508 \pm 1505(20840-23)$ \\
in 24 hours (Maximum Minimum) &
\end{tabular}

Table- IV shows association between age and dislipidaemia, the highest no of dyslidaemia was 14 which were found in age group 61-70 years whereas the highest (11) patients of without dyslipidaemia was found in age group 51-60 years. The mean of dyslipidaemia and without dyslipidaemia patients were $60.7 \pm 13.1$ and $58 \pm 10.3$ respectively where p-value was 0.424

Table IV: Association between age and dyslipidaemia $(\mathrm{n}=60)$

\begin{tabular}{lccc}
\hline Age (years) & $\begin{array}{c}\text { Dyslipidaemia } \\
(\mathbf{n}=\mathbf{4 0})\end{array}$ & $\begin{array}{c}\text { Without } \\
\text { dyslipidaemia } \\
(\mathbf{n}=\mathbf{2 0})\end{array}$ & p value \\
\cline { 2 - 3 } & $\mathbf{n}(\%)$ & $\mathbf{n}(\%)$ & \\
\hline$<50$ & $9(22.5)$ & $3(15.0)$ & \\
$51-60$ & $13(32.5)$ & $11(55.0)$ & \\
$61-70$ & $14(35.0)$ & $4(20.0)$ & \\
$>70$ & $4(10.0)$ & $2(10.0)$ & \\
\hline Mean \pm SD & $60.7 \pm 13.1$ & $58.0 \pm 10.3$ & 0.424 \\
Range (min-max) & $40-84$ & $42-81$ & \\
\hline
\end{tabular}

$P$ value was calculated using from unpaired t-test

Table- IV shows association between age and dislipidaemia, the highest no of dyslidaemia was 14 which were found in age group 61-70 years whereas the highest (11) patients of without dyslipidaemia was found in age group 51-60 years. The mean of dyslipidaemia and without dyslipidaemia patients were $60.7 \pm 13.1$ and $58 \pm 10.3$ respectively where p-value was 0.424

Table V: Association between gender and dyslipidaemia $(\mathrm{n}=60)$

\begin{tabular}{lccc}
\hline Sex & $\begin{array}{c}\text { Dyslipidaemia } \\
(\mathbf{n}=40)\end{array}$ & $\begin{array}{c}\text { Without } \\
\text { dyslipidaemia } \\
(\mathbf{n}=\mathbf{2 0})\end{array}$ & p value \\
\cline { 2 - 3 } & \multicolumn{2}{c}{$\mathbf{n}(\%)$} & \\
\hline Male & $\mathbf{n}(\%)$ & $8(40.0)$ & 0.200 \\
Female & $17(42.5)$ & $12(60.0)$ & \\
\hline
\end{tabular}

$\mathrm{p}$ value was extracted using chi square test
Table V shows association between gender and dyslipidaemia. Dyslipidaemic male was $57 \%$ and female was $42.5 \%$ whereas absent of dyslipidaemia in male was $40 \%$ and female was $60 \%$. This was statistically significant.

Table VI: Association between lipid profile with sex $(\mathrm{n}=60)$

\begin{tabular}{lccc}
\hline Lipid profile & $\begin{array}{c}\text { Male } \\
(\mathbf{n}=31)\end{array}$ & $\begin{array}{c}\text { Female } \\
(\mathbf{n}=29)\end{array}$ & p value \\
\cline { 2 - 3 } & Mean \pm SD & Mean \pm SD & \\
\hline Cholesterol $(\mathrm{mg} / \mathrm{dl})$ & $211.1 \pm 48.9$ & $231.3 \pm 59.2$ & 0.154 \\
Triglyceride $(\mathrm{mg} / \mathrm{dl})$ & $218.9 \pm 89.6$ & $254.9 \pm 98.7$ & 0.144 \\
HDL $(\mathrm{mg} / \mathrm{dl})$ & $38.1 \pm 16.2$ & $42.1 \pm 13.1$ & 0.299 \\
LDL $(\mathrm{mg} / \mathrm{dl})$ & $124.5 \pm 27.8$ & $138.6 \pm 36.4$ & 0.096
\end{tabular}

$P$ value reached from unpaired $t$-test

Table- VI shows distribution by association between lipid

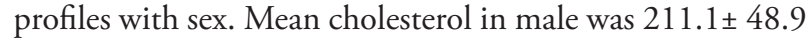
$\mathrm{mg} / \mathrm{dl}$ where in female it was $231.3 \pm 59.2$, mean triglyceride was in male $218.9 \pm 89.6 \mathrm{mg} / \mathrm{dl}$ but in female $254.9 \pm 98.7 \mathrm{mg} / \mathrm{dl}$ then mean HDL represented in male $38.1 \pm 16.2 \% \mathrm{mg} / \mathrm{dl}$ and in female that was $42.1 \pm 13.1 \mathrm{mg} / \mathrm{dl}$ followed by mean LDL in male was $124.5 \pm 27.8 \mathrm{mg} / \mathrm{dl}$ but in that was in female $138.6 \pm 36.4 \mathrm{mg} / \mathrm{dl}$. Table represented that women were more vulnerable than men.

Table VII: Comparison of mean total ventricular beats in subjects with and without dyslipidaemia $(\mathrm{n}=60)$

\begin{tabular}{lccc}
\hline & $\begin{array}{c}\text { Dyslipidaemia } \\
(\mathbf{n}=40)\end{array}$ & $\begin{array}{c}\text { Without dyslipidaemia } \\
(\mathbf{n}=40)\end{array}$ & p value \\
\cline { 2 - 3 } & Mean \pm SD & Mean \pm SD & \\
\hline Total ventricular & $13472 \pm 4872$ & $8754 \pm 2689$ & $0.001^{*}$ \\
beats in 24 hours & & & \\
\hline * $=$ significant \\
p value reached from unpaired t-test
\end{tabular}

Table- VII showing total ventricular beats in 24 hours among dyslipidaemia group which is significantly more in number in comparison to group without dyslipidemia showing significant role of dyslipidemia causing arrhythmia.

Table VIII: Comparison of mean total supraventricular beats in subjects with and without dyslipidaemia $(n=60)$

\begin{tabular}{lccc}
\hline $\begin{array}{c}\text { Dyslipidaemia } \\
(\mathbf{n}=40)\end{array}$ & $\begin{array}{c}\text { Without dyslipidaemia } \\
(\mathbf{n}=40)\end{array}$ & p value \\
\cline { 2 - 3 } & Mean \pm SD & Mean \pm SD & \\
\hline Total supraventricular $12031 \pm 4201$ & $8522 \pm 2099$ & $0.001^{*}$ \\
beats in 24 hours & & \\
${ }^{*}=$ significant & & \\
P value reached from unpaired t-test &
\end{tabular}


Table showing Total supraventricular beats in 24 hours among dyslipidemia group which is significantly more in number in comparison to group without dyslipidemia showing significant role of dyslipidemia causing arrhythmia

\section{DISCUSSION:}

Total number of patients was 60 with male predominance and mean age was $59.58 \pm 11.38$ years. Common co-morbidities in this study were hypertension, IHD and dyslipidaemia. Gunalp et al. found hypertension, IHD and stroke as co-morbid conditions.13 The study subjects had mean pulse $78 \pm 15$ (55-98) beat/minute and mean maximum and minimum heart rate were $114 \pm 22$ and $57 \pm 14$ beats respectively. Ewing et al. found in his study that maximum heart rate was $114 \pm 10$ beats/ min and minimum rate was $66 \pm 9$ beats / $\mathrm{min}$ in 24 hours Holter ECG findings in diabetic subjects with arrhythmia.14 Brownlee et al. Observed that diabetic subjects with arrhythmic had maximum heart rate was $118 \pm 15$ beats/min and minimum heart rate was $79 \pm 10$ beats $/ \min .15$ Fasting Blood Glucose(FBG) and $\mathrm{HbAlc} \%$ level were $19.32 \mathrm{mmol} / \mathrm{l}$ and $12.34 \%$ respectively. Stamler et al. observed that mean \pm SD RBS and $\mathrm{HbA1C} \%$ levels were $20.29 \pm 8.61 \mathrm{mmol} / \mathrm{l}$ and $10.48 \pm 4.11$ respectively. 16 Jocoby et al. seen that mean $\pm S D$ RBS and $\mathrm{HbA1C} \%$ levels were $18.29 \pm 7.55 \mathrm{mmol} / \mathrm{l}$ and $11.37 \pm 5.92$ respectively.17 Mean cholesterol level was $222.58 \pm 55.51 \mathrm{mg} / \mathrm{dl}$, mean triglyceride $241.26 \pm 98.81$ $\mathrm{mg} / \mathrm{dl}$, LDL $135.53 \pm 35.61 \mathrm{mg} / \mathrm{dl}$ and HDL $41.46 \pm 15.46$ $\mathrm{mg} / \mathrm{dl}$ in our study. Gomez et al. found almost similar lipid profile reports. 18

Regarding ventricular ectopics, it was seen that $40 \%$ had single PVC's, $20 \%$ had triplets, $16.67 \%$ had couplets and $13.33 \%$ had ventricular run in our study. In case of supraventricular ectopics, it was seen that $43.33 \%$ subjects had Single PAC's, 33.33\% atrial run, 25\% had atrial pairs. James et al. in a similar study found that mean total supraventricular beats in 24 hours was 3705 whereas, PAC's was observed in $41 \%$ subjects and atrial run in $16 \%$ cases. 19 Regarding supraventricular events, another study by Binici et al. revealed that mean total supraventricular beats in 24 hours was 3929 whereas, PAC's was observed in 70\% subjects and atrial run was observed in $42 \%$ patients. 20 Regarding ventricular events Adabaq et al.21 found mean total ventricular beats in 24 hours was 3256 and single PVC's were noted in $42 \%$ subjects in their study. It was seen that statistically significant difference in mean ventricular beats and supraventricular beats in 24 hours between controlled diabetes and those with uncontrolled diabetes.

Present study revealed that male were higher in dyslipidaemia group compared to groups without dyslipidaemia but that difference was not statistically significant $(\mathrm{p}>0.05)$. The mean cholesterol, TG, HDL and LDL were also not statistically significant $(p>0.05)$ between male and female patients. O'Meara et al. study showed higher prevalence of dyslipidemia among men than women.22 Different study also agreed with our observation. They showed the mean values of LDL cholesterol, HDL cholesterol, and triglycerides was not statistically significant between male and female patients.23-24 Badea et al. the mean values $\pm \mathrm{SD}$ of serum lipids and fasting blood glucose is noticed that the mean values of serum TG were slightly elevated. Total Cholesterol levels were close to the limits specified by guidelines for diabetic patients and for patients with cardiovascular diseases, with no significant differences between males and females.25 Mean values of HDL-C were decreased. HDL-C levels were found to be higher in females $(37.22 \pm 10.75)$ com $\neg$ pared with males $(35.36 \pm 7.70)$, with statistical signifincance $(\mathrm{p}=0.00081) .26 \mathrm{Few}$ studies have shown that postmenopausal women present with a significant increase of TC, LDL-C and TG values, but insignificant decrease of HDL-C.27-28 On the other hand, a comparative study of plasma lipid profile tests in healthy young population showed that TC and LDL-C levels were significantly increased in men. The same study showed that HDL-C levels were significantly decreased in men compared with BMI and age matched women.

Present study revealed that significant difference was seen in mean ventricular beats $13472 \pm 4872,8754 \pm 2689$ in 24 hours between groups with and without dyslipidaemia. Significant difference was also seen in mean supraventricular beats $12031 \pm 4201,8522 \pm 2099$ in 24 hours between groups with and without dyslipidaemia. Liu et al. comparison of lipid profiles between patients with VT/VF and controls revealed that patients experiencing VT/VF had higher levels of TC, LDL-C and triglyceride at 3 months after MI, and a higher level of LDL-C at admission.29

\section{CONCLUSIONS:}

Arrhythmia is more common among diabetic patients having dyslipidaemia than those without dyslipidaemia. Dyslipidaemia may play an important role in arrhythmogenesis in diabetic case. Therefore dyslipidaemia should be controlled adequately to combat arrhythmia and IHD in diabetic cases.

\section{REFERENCES:}

1. M.J. Field, L. Burnett, D.R. Sullivan, P.Stewart Clinical biochemistry and metabolism, In: Brian R. Walker, Nicki R. Colledge, Stuart H. Ralston, Ian D. Penman (eds.) Davidson's Principles \& Practice of Medicine 22nd edition Edinburgh, Churchill Livingstone Elsevier; 2014, p. 452 - 3. 2. Myerburg RJ, Kessler KM, Castellanos A. Sudden cardiac death: epidemiology, transient risk, and intervention assessment. Ann Intern Med 1993;119:1187-97.

3. Myerburg RJ, Interian A Jr, Mitrani RM, Kessler KM, Castellanos A. Frequency of sudden cardiac death and profiles of risk. Am J Cardiol 1997; 80:10F-19F. 
4. Zipes DP, Wellens HJJ. Sudden cardiac death. Circulation 1998;98: 2334-51.

5. The Long-Term Intervention with Pravastatin in Ischaemic Disease (LIPID) Study Group. Prevention of cardiovascular events and death with pravastatin in patients with coronary heart disease and a broad range of initial cholesterol levels. N Engl J Med 1998;339:1349-57.

6. LaRosa JC, He J, Vupputuri S. Effect of statins on risk of coronary disease: a meta-analysis of randomized controlled trials. JAMA 1999;282:2340-6.

7. Randomised trial of cholesterol lowering in 4444 patients with coronary heart disease: the Scandinavian Simvastatin Survival Study (4S). Lancet 1994;344:1383-9.

8. Galli A, Ambrosini F, Lombardi F. Holter Monitoring and Loop Recorders: From Research to Clinical Practice. Arrhythmia \& Electrophysiology Review 2016;5(2):136-43.

9. Zimetbaum P, Goldman A. Ambulatory arrhythmia monitoring: choosing the right device. Circulation. 2010;122:1629-36.

10. Brignole M, Vardas P, Hoffman E, Huikuri H, Moya A, Ricci $R$, et al. Indications for the use of diagnostic implantable and external ECG loop recorders. Europace 2009;11:671-87.

11. Giada F, Bertaglia E, Reimers B, Noventa D, Raviele A. Current and emerging indications for implantable cardiac monitors. Pacing Clin Electrophysiol 2012;35:1169-78.

12. Liu YB, Wu CC, Lu LS, Su MJ, Lin CW, Lin SF, et al. Sympathetic nerve sprouting, electrical remodeling, and increased vulnerability to ventricular fibrillation in hypercholesterolemic rabbits. Circ Res 2003;92:1145-52.

13. Gunalp M, Atalar E, Coskun F, Yilmaz A, Aksoyek S, Aksu NM, Sivri B. Holter monitoring for 24 hours in patients with thromboembolic stroke and sinus rhythm diagnosed in the emergency department. Adv Ther. 2006;23(6):854-60.

14. Ewing DG, Borsey DQ, Travis P, Bellavere F, Neilson JJM, Clarke BF. Abnormalities of Ambulatory 24-hour Heart Rate in Diabetes Mellitus Diabetes 1983; 32: 101.

15. Brownlee $M$, The pathobiology of diabetic complications: A unifying mechanism, Diabetes, 2005; 54:1615-25.

16. Stamler J, Vaccaro O, Neaton JD, Wentworth D, Multiple Risk Factor Intervention Trial Research Group. Diabetes, other risk factors, and 12-yr cardiovascular mortality for men screened in the multiple risk factor intervention trial. Diabetes Care 1993; 16:434-44.

17. Jacoby RM, Nesto RW. Acute myocardial infarction in the diabetic patient: pathophystology, clinical course and prognosis. J Am Coll Cardiol 1992; 20:736-44.

18. Gomez MJ, Roldan I, Díez JL, García K, Sanmiguel D, Salvador A et al. Predictive value of differential pulse pressure in the diagnosis of silent myocardial ischemia in patients with type-2 diabetes. Rev Esp Cardiol. 2007; 60(5): 543.

19. James J.H, Kumar S, Thomas L, Thomas S. Supraventricular ectopy and recurrence of atrial fibrillation after electrical cardioversion. Europace 2006; 8: 341.

20. Binici Z, Intzilakis T, Nielsen OW, Kober L, Sajadieh A, Excessive Supraventricular Ectopic Activity and Increased Risk of Atrial Fibrillation and Stroke. Circulation. 2010; 121: 1904-11.

21. Adabag A, Susan A, Kuskowski MA, Zenovich AG, Maron BJ, Spectrum and prognostic significance of arrhythmias on ambulatory Holter electrocardiogram in hypertrophic Cardiomyopathy. Am Coll Cardiol. 2005; 45(5):697-704.

22. O'Meara JG, Kardia SL, Armon JJ, Brown CA, Boerwinkle E, Turner ST. Ethnic and sex differences in the prevalence, treatment, and control of dyslipidemia among hypertensive adults in the GENOA study. Arch Intern Med. 2004;164(12):1313-8.

23. Stern N, Grosskopf I, Shapira I, Kisch E, Isaacov A, Limor R, et al. Risk factor clustering in hypertensive patients: impact of the reports of NCEP-II and second joint task force on coronary prevention on JNC-VI guidelines. J Intern Med. 2000;248:203.

24. Kastarinen MJ, Nissinen AM, Vartiainen EA, Jousilahti PJ, Korhonen HJ, Puska PM, et al. Blood pressure levels and obesity trends in hypertensive and normotensive Finnish population from 1982 to 1997. J Hypertens. 2000;18:25562.

25. Badea AR, Nedelcu L, Valeanu M, Zdrenghea D. The Relationship between Serum Lipid Fractions and Heart Rate Variability in Diabetic Patients with Statin Therapy. Clujul Med. 2014; 87(3): 152- 8.

26. Liu CC, Kuo TB, Yang CC. Effects of estrogen on gender-related autonomic differences in humans. Am J Physiol Heart Circ Physiol. 2003;285:H2188- 93.

27. Roy A, Kundu D, Mandal T, Bandyopadhyay U, Ghosh E, Ray D. A comparative study of heart rate variability tests and lipid profile in healthy young adult males and females. Niger J Clin Pract. 2013;16(4):424- 8.

28. Fu CH, Yang CC, Lin CL, Kuo TB. Alteration of cardiovascular autonomic functions by vegetarian diets in postmenopausal women is related to LDL cholesterol levels. Chin J Physiol 2008;51:100-105.

29. Liu YB, Wu CC, Lee CM, Chen WJ, Wang TD, Chen PS, et al. Dyslipidemia is associated with ventricular tachyarrhythmia in patients with acute ST-segment elevation myocardial infarction. J Formos Med Assoc. 2006;105(1):17-24. 